\title{
CHOLESTEROL METABOLISM IN MAN
}

\author{
BY MARVIN D. SIPERSTEIN AND ANNE W. MURRAY \\ (From the Laboratory of Chemical Pharmacology, National Heart Institute, National Institutes \\ of Health, Public Health Service, U. S. Department of Health, Education, and \\ Welfare, Bethesda, Md.)
}

(Submitted for publication April 11, 1955; accepted May 25, 1955)

It has been previously demonstrated that, in the rat, the major metabolic pathway of cholesterol involves the conversion of this molecule to bile acids $(1,2)$. These are excreted into bile and after repeated enterohepatic circulation (3) are finally eliminated in the feces, still in the form of bile acids. Over 80 per cent of the body's cholesterol was found to be metabolized in this manner $(1,2)$.

In rat bile, the chief bile acid resulting from cholesterol metabolism has been identified specifically as the taurine conjugate of cholic acid (4-6).

Since it is known that this reaction is not limited to the rat (7), there is some reason to expect that cholesterol is metabolized primarily by way of bile acids in man as well. Quantitative studies of the pathways of cholesterol breakdown in human beings have not, however, been previously published. Hellman and his co-workers have administered $\mathrm{C}^{14}$-labeled cholesterol to patients and stated that this sterol is converted to cholic acid and to steroid hormones; however, no information on the quantitative importance of these compounds in cholesterol metabolism was reported (8).

The purpose of the present study was to assess the quantitative significance of the various routes of cholesterol excretion and to determine the major end-products of cholesterol metabolism in man.

\section{MATERIAL AND METHODS}

\section{Cholesterol-4- $C^{16}$}

The labeled cholesterol was obtained from Radioactive Products, Detroit, Mich., and had a specific activity of $5 \mu \mathrm{C}$ per mg. Before use the cholesterol was purified by digitonin precipitation and chromatography on alumina as previously described (6). The sterol was administered intravenously as a Tween 20 , saline solution (9).

\section{Treatment of patient}

The subject of this investigation was a 54-year-old male who three weeks prior to beginning the study was subjected to a cholecystectomy (diagnosis: cholecystitis and cholelithiasis). At the time of surgery a T-tube was inserted into his common bile duct. An inflatable balloon located below the distal arm of the $T$ allowed complete drainage of bile to the exterior when desired.

The experiment was initiated by inflating the balloon and immediately injecting intravenously 3 microcuries $(600 \gamma)$ of cholesterol-4-C $C^{14}$. All bile was then collected for a period of 50 hours. At the end of this time the balloon was deflated and bile was again allowed to enter the duodenum. Feces were saved during the 50 hours of biliary drainage and for 6 days thereafter. Urine was likewise obtained both during the period of bile collection and for the following 40 hours. All samples were frozen immediately after collection and were stored at $-10^{\circ}$ C. until analyzed. A single, half-hour sample of expired air was collected 29 hours after the cholesterol administration.

\section{Bile}

Total biliary $\mathrm{C}^{14}$ was assayed by directly mounting an aliquot of bile on an aluminum planchet and counting the dried sample in a Robinson-type flow-gas counter. All counts were corrected for self absorption.

\section{Total bile acid-C $\mathrm{C}^{\mathrm{4}}$}

Bile acid-C $\mathrm{C}^{14}$ was determined as described previously (2). Samples of the bile were saponified in $4 \mathrm{~N} \mathrm{NaOH}$ at $125^{\circ} \mathrm{C}$. for 2 hours. They were shaken three times with approximately a tenfold excess of petroleum ether to extract the radioactivity contained as nonsaponifiable compounds. Following acidification the bile was again shaken with petroleum ether to extract fatty acids. Then ethyl ether extraction was used to obtain the bile acid fraction which was finally purified through the Doubilet procedure (10) to yield total bile acid-C $\mathrm{C}^{14}$.

\section{Isolation of bile acids by use of the carrier technique}

In order to determine the quantitative importance of a specific bile acid involved in cholesterol excretion, carrier amounts (100 to $500 \mathrm{mg}$.) of the pure nonradioactive bile acid were added to the bile sample. This was then saponified at $125^{\circ} \mathrm{C}$. in $4 \mathrm{~N} \mathrm{NaOH}$ for 2 hours. The solution containing saponified $\mathrm{C}^{14}$-bile acids and the carrier bile acid was next acidified and the resulting gummy precipitate removed, washed with water, and dried in vacuo. Cholic acid was recrystallized directly from this gum by using ethyl acetate as the solvent. Desoxycholic acid was isolated by crystallizing from methyl ethyl ketone, and recrystallizing from acetone. 
Weighed portions of the crystals were counted after being redissolved in ethanol and dried in the planchets.

\section{Chromatography}

Paper chromatography of the bile was carried out with Whatman No. 1 filter paper in a collidine, ammonia, water system as previously described (6). The bile acids were visualized by spraying the dried chromatogram with 50 per cent antimony trichloride in glacial acetic acid. When an estimate of the $\mathrm{C}^{14}$ content of the bile acid spots was desired, one-quarter inch strips on either side of the chromatogram were sprayed with antimony trichloride, to determine the positions of the bile acids on the paper. The bile acids in the unsprayed, central portion of the chromatogram were then eluted directly into planchets and the eluate was dried and counted.

\section{Feces}

Feces were extracted with three portions of boiling ethyl alcohol for a total period of one hour. The residue was then placed in a Soxhlet apparatus and extracted for 12 more hours with ethyl alcohol. An aliquot of the pooled extracts was counted without further purification.

\section{Urine}

Aliquots of urine were plated directly and counted in the Robinson counter.

\section{RESULTS}

\section{Routes of excretion of cholesterol end-products}

During the course of the 50-hour collection period 39.0 per cent of the administered $\mathrm{C}^{14}$ was recovered in the subject's bile (Figure 1). It was felt inadvisable to deprive the patient of his bile for a longer period of time; however, it seems reasonable to assume from the curve shown in Figure 1 that cholesterol end-products would have continued to be eliminated by this route at a comparable rate.

That bile does constitute the chief route of cholesterol excretion in man is strongly suggested by comparing the results of $\mathrm{C}^{14}$ analysis of the bile with that of the acholic feces, urine and expired air. In the same time period during which 39 per cent of the injected $\mathrm{C}^{14}$ was being eliminated in the bile, only 0.5 per cent of the cholesterol-4-C $C^{14}$ was found in the feces and 0.1 per cent in the urine. No $\mathrm{C}^{14} \mathrm{O}_{2}$ was detected in the expired air. As summarized in Table $I$, therefore, it is clear that over 98 per cent of the excreted $\mathrm{C}^{14}$ was eliminated by way of bile.

The feces and urine samples obtained after the 50-hour period of bile collection were found to
BILIARY EXCRETION OF CHOLESTEROL-4-C14 IN MAN

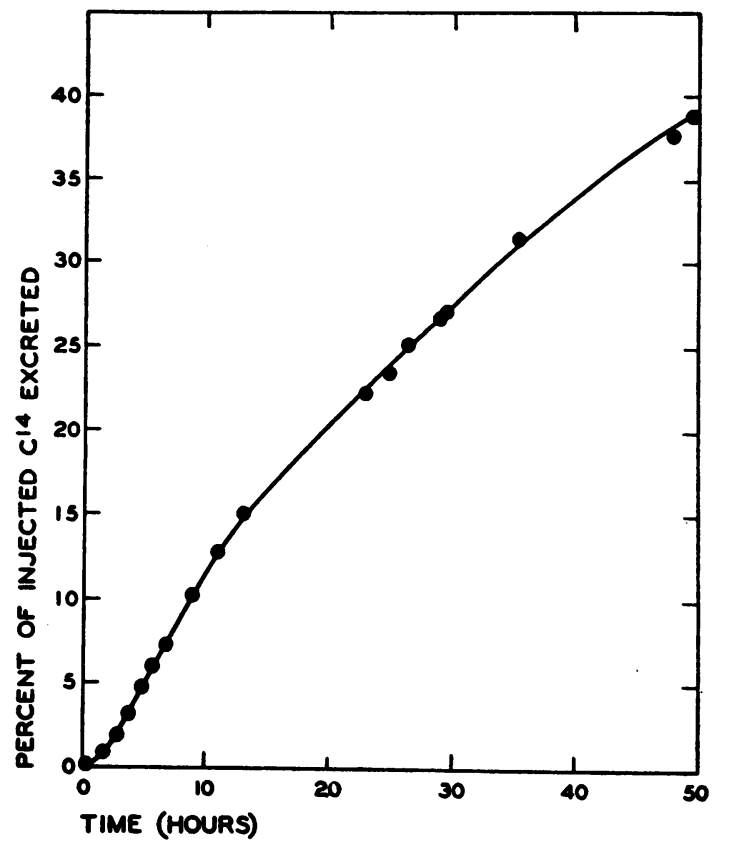

Fig. 1. Cumulative Excretion of C $C^{14}$ into Bile FolLOWING INJECTION OF ChOLESTERoL-4-C ${ }^{4}$

contain, respectively, 4.1 and 0.06 per cent of the administered cholesterol-C ${ }^{14}$.

\section{Nature of the biliary end-products of cholesterol metabolism}

The $\mathrm{C}^{14}$-containing end-products of cholesterol metabolism were identified by the three methods described in the experimental section.

1. Isolation of (a) the nonsaponifiable fraction which includes cholesterol, dihydrocholesterol and coprosterol; (b) the fatty acid fraction; and (c) the total bile acid fraction. Assay of these three fractions indicated (Table II) that cholesterol is excreted in bile primarily as a bile acid(s). In

TABLE I

Routes of excretion of cholesterol-4-C14 in man *

\begin{tabular}{lc}
\hline \multicolumn{1}{c}{ Source } & $\begin{array}{c}\text { Per cent of } \\
\text { excreted Cit }\end{array}$ \\
\hline Bile & 98.5 \\
Acholic feces & 1.3 \\
Urine & 0.2 \\
$\mathrm{CO}_{2}$ & 0.0
\end{tabular}

* Period of collection was 50 hours, except for the $\mathrm{CO}_{2}$ collection where a single one-half hour sample was taken. Total $C^{14}$ excretion was 39.6 per cent of the administered 
TABLE II

Nature of the biliary end-products of cholesterol metabolism

\begin{tabular}{|c|c|c|}
\hline $\begin{array}{l}\text { Time } \\
\text { period } \\
\text { (hrs.) }\end{array}$ & Fraction & $\begin{array}{l}\text { Per cent } \\
\text { of total } \\
\text { biliary } \mathrm{Cu} \\
\text { in fraction }\end{array}$ \\
\hline $3-4$ & $\begin{array}{l}\text { Nonsaponifiable } \\
\text { Fatty acid } \\
\text { Bile acid }\end{array}$ & $\begin{array}{r}11.2 \\
.1 \\
88.7\end{array}$ \\
\hline $7-9$ & $\begin{array}{l}\text { Nonsaponifiable } \\
\text { Fatty acid } \\
\text { Bile acid }\end{array}$ & $\begin{array}{r}7.6 \\
.2 \\
92.2\end{array}$ \\
\hline $29-36$ & $\begin{array}{l}\text { Nonsaponifiable } \\
\text { Fatty acid } \\
\text { Bile acid }\end{array}$ & $\begin{array}{r}10.2 \\
.4 \\
89.4\end{array}$ \\
\hline $36-48$ & $\begin{array}{l}\text { Nonsaponifiable } \\
\text { Fatty acid } \\
\text { Bile acid }\end{array}$ & $\begin{array}{r}7.0 \\
.4 \\
92.6\end{array}$ \\
\hline
\end{tabular}

the four bile acid samples analyzed only about 10 per cent of the $\mathrm{C}^{14}$ was found in the nonsaponifiable fraction; negligible activity was present in the form of fatty acids. On the other hand, between 89 and 93 per cent of the biliary $C^{14}$ was found in the bile acids, isolated by ethyl ether extraction and precipitation according to the Doubilet procedure.

2. Isolation by the carrier technique. Identification of the specific bile acids to which cholesterol is converted was accomplished by adding known bile acids to the bile, followed by recrystallization of the recovered bile acids to constant specific activity (see Experimental). It was found (Table III) that most of the radioactivity was present in bile as cholic acid. Desoxycholic acid was found to comprise a small per cent of the cholesterol excretion products in both of the samples analyzed.

3. Paper chromatography. Paper chromatography of a bile sample collected between the 36th and 48th hours was performed in order to confirm the results of the above two procedures and

TABLE III

Identification of the bile acid end-products of cholesterol metabolism as isolated by the carrier technique

\begin{tabular}{cccc}
\hline \hline & $\begin{array}{c}\text { Per cent of } \\
\text { total C14 of } \\
\text { sample in } \\
\text { cholic acid } \\
\text { desoxycholic } \\
\text { Time }\end{array}$ & \multicolumn{2}{c}{$\begin{array}{c}\text { Per cent of total bile } \\
\text { acid C14 in }\end{array}$} \\
\cline { 3 - 5 } period & acid & CA & DCA \\
\hline $29-36$ & 97 & 90 & 7 \\
$36-48$ & 90 & 90 & 7 \\
\hline
\end{tabular}

also to further identify the major cholesterol endproducts in bile.

On spraying a chromatogram of human bile with the antimony trichloride solution four bands became visible (Figure 2). The first with an $R_{t}$ of 0.49 to 0.53 was by far the darkest and was identified with pure standards as glycocholic acid. Immediately above the glycocholic acid was seen a band giving the purple color of a dihydroxylated bile acid. It is likely that this is the glycine conjugate of the desoxycholic acid isolated by the carrier technique since taurodesoxycholic migrates much faster than the observed band. This band no doubt also contains glycochenodesoxycholic acid. At an $R_{f}$ of 0.75 a small amount of taurocholic acid color is usually visible. Finally, cholesterol and perhaps monohydroxy bile acids are seen at the front.

The $\mathrm{C}^{14}$ content of these bands could be assayed only approximately since there is undoubtedly some overlapping of activity on the paper. The results are given in Figure 2. The major portion of the $\mathrm{C}^{14}$ was definitely present in the glycocholic acid band with the small amounts of $C^{14}$ in the taurocholic acid, glycodesoxycholic acid and at the front making up the remainder of the activity.

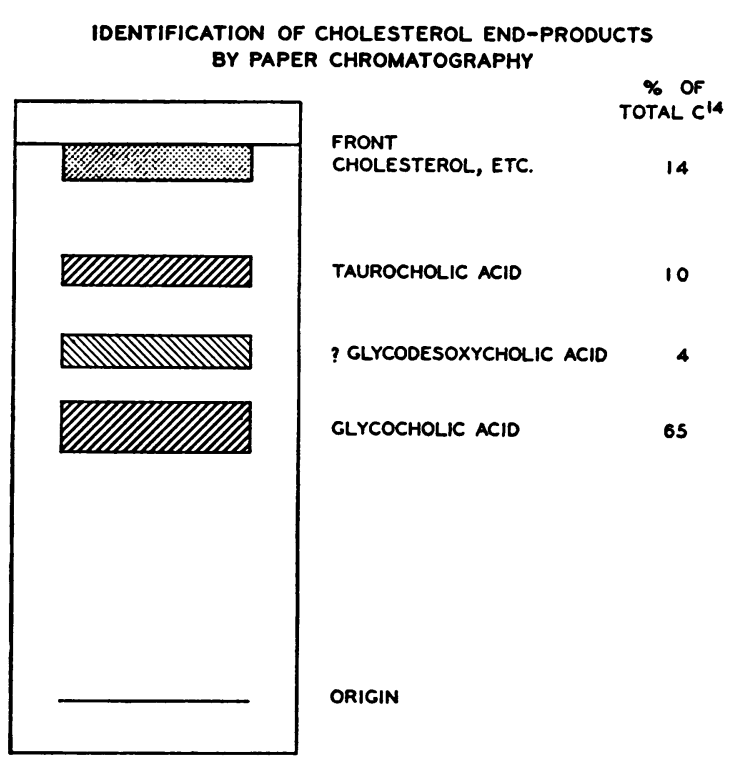

Fig. 2. Schematic Drawing of a Paper Chromatogram of Bile Sample Taken from the 36th to the 48th Hour after Cholesterol-4-C ${ }^{14}$ Injection

For details see text. 
These results are in good agreement with those obtained by use of the carrier technique.

\section{DISCUSSION}

Until recently it has been the general opinion that the 27-carbon neutral sterol, coprosterol, was the major end-product of cholesterol metabolism. Cholesterol itself and dihydrocholesterol were believed to make up most of the remainder of the body's sterol excretion while bile acid synthesis was assumed to play a relatively minor role in this process (11-13).

That coprosterol is not the chief end-product of cholesterol metabolism has now been amply shown in the rat. Further, it has been demonstrated in this species that most of the body cholesterol is metabolized by way of bile acids and that it is primarily as bile acids that cholesterol is excreted into both the bile and the feces $(1,2)$.

Evidence that man, too, converts a large fraction of his body cholesterol to bile acids before excretion is presented here.

In a human subject given cholesterol-4-C ${ }^{14}$, 39.6 per cent of the administered sterol was found to be eliminated by all routes of excretion in a 50-hour period. Of this amount, however, fully 98 per cent was excreted by way of bile while only 1.3 and 0.2 per cent were lost in the acholic feces and urine, respectively. Since approximately 90 per cent of the cholesterol- $\mathrm{C}^{\mathbf{1 4}}$ excreted in bile could be recovered as bile acids, it can be concluded that in this experiment at least 87 per cent of the total cholesterol had been converted to bile acids before excretion.

The finding that cholic acid is the chief bile acid end-product of cholesterol metabolism in the bile of man is in keeping with the similar observation in the rat $(4,6)$. In man, however, the labeled cholic acid was present as the glycine conjugate, whereas in rat bile taurocholic acid constituted the major labeled bile salt $(5,6)$. This finding was not surprising since glycocholic acid has long been known to be the predominant bile salt in human bile (14) and so might be expected to be an important cholesterol metabolite as well.

At present the most plausible scheme of cholesterol breakdown in the rat involves the conversion of cholesterol to desoxycholic acid (15) and the subsequent hydroxylation of desoxycholic acid to yield cholic acid (16). The demonstration in the present study that cholesterol can be converted to desoxycholic acid as well as to cholic acid is consistent with the idea that such a pathway may also be present in man.

Finally the inability of the human body to metabolize cholesterol-4- $\mathrm{C}^{14}$ to $\mathrm{C}^{14} \mathrm{O}_{2}$ also agrees with previous observations that neither the rat nor the dog can perform this oxidation $(1,9,17)$ and confirms the similar finding by Hellman and his co-workers $(8,18)$ in man.

\section{SUMMARY}

1. Cholesterol-4- $\mathrm{C}^{\mathbf{1 4}}$ was injected intravenously into a man with complete biliary drainage. The routes of excretion and the major compounds to which cholesterol is converted were then studied.

2. Of the administered cholesterol 39.6 per cent was eliminated by all routes of excretion in a 50-hour period.

3. Over 98 per cent of the excreted cholesterol appeared in the bile, 1.3 per cent in the acholic feces, and 0.2 per cent in the urine. No $\mathrm{C}^{14} \mathrm{O}_{2}$ was found in the expired air.

4. It has been shown that in man the major pathway of cholesterol metabolism involves the conversion of cholesterol to bile acids.

5. The chief excretory product of cholesterol in the bile of man has been identified as glycocholic acid.

\section{REFERENCES}

1. Siperstein, M. D., and Chaikoff, I. L., C Ch-Cholesterol. III. Excretion of carbons 4 and 26 in feces, urine, and bile. J. Biol. Chem., 1952, 198, 93.

2. Siperstein, M. D., Jayko, M. E., Chaikoff, I. L., and Dauben, W. G., Nature of the metabolic products of $\mathrm{C}^{14}$-cholesterol excreted in bile and feces. Proc. Soc. Exper. Biol. \& Med., 1952, 81, 720.

3. Siperstein, M. D., Hernandez, H. H., and Chaikoff, I. L., Enterohepatic circulation of carbon 4 of cholesterol. Am. J. Physiol., 1952, 171, 297.

4. Bergström, S., The formation of bile acids from cholesterol in the rat. K. Fysiograf. Sällskap. Lund, Förhandl., 1952, 22, No. 16.

5. Bergström, S., and Norman, A., Metabolic products of cholesterol in bile and feces of rat. Steroids and bile acids. Proc. Soc. Exper. Biol. \& Med., 1953, 83, 71.

6. Siperstein, M. D., Harold, F. M., Chaikoff, I. L., and Dauben, W. G., C ${ }^{16}$-Cholesterol. VI. Biliary end-products of cholesterol metabolism. J. Biol. Chem., 1954, 210, 181. 
7. Bloch, K., Berg, B. N., and Rittenberg, D., The biological conversion of cholesterol to cholic acid. J. Biol. Chem., 1943, 149, 511.

8. Hellman, L., Rosenfeld, R., Fukushima, D., Eidinoff, M., Brunschwig, A., and Gallagher, T., The major pathways of steroid metabolism in man. J. Clin. Invest., 1953, 32, 573 (Abst.).

9. Meier, J. R., Siperstein, M. D., and Chaikoff, I. L., $\mathrm{C}^{14}$-Cholesterol. IV. Oxidation of carbons 4 and 26 to carbon dioxide by surviving tissues. J. Biol. Chem., 1952, 198, 105.

10. Doubilet, H., Differential quantitative analysis of bile acids in bile and in duodenal drainage. $\mathrm{J}$. Biol. Chem., 1936, 114, 289.

11. Bills, C. E., Physiology of the sterols, including vitamin D. Physiol. Rev., 1935, 15, 1.

12. Weinhouse, S., The blood cholesterol. Arch. Path., 1943, 35, 438.

13. Bloch, K., The intermediary metabolism of cholesterol. Circulation, 1950, 1, 214.
14. Sobotka, H., Physiological Chemistry of the Bile. Baltimore, Williams and Wilkins Co., 1937.

15. Siperstein, M. D., and Murray, A. W., Unpublished observations cited in Siperstein, M. D., and Chaikoff, I. L., Conversion of Cholesterol to Bile Acids, Symposium on Cholesterol Metabolism, Federation Proc., 1955, to be published.

16. Bergström, S., Rottenberg, M., and Sjövall, J., Uber den Stoff wechsel der Cholsäure in der Ratte. X. Mitteilung über Steroide und Gallensauren. Ztschr. f. physiol. Chem., 1953, 295, 278.

17. Chaikoff, I. L., Siperstein, M. D., Dauben, W. G., Bradlow, H. L., Eastham, J. F., Tomkins, G. M., Meier, J. R., Chen, R. W., Hotta, S., and Srere, P. A., C Ch-Cholesterol. II. Oxidation of carbons 4 and 26 to carbon dioxide by the intact rat. J. Biol. Chem., 1952, 194, 413.

18. Hellman, L., Rosenfeld, R. S., Eidinoff, M. L., Fukushima, D. K., Gallagher, T. F., Wang, C., and Adlersberg, D., Isotopic studies of plasma cholesterol of endogenous and exogenous origins. J. Clin. Invest., 1955, 34, 48. 